\title{
Microestrutura e Propriedades Mecânicas de um Aço para Trilhos Ferroviários Soldado por Centelhamento
}

\author{
Rodrigo Rangel Porcaro ${ }^{1}$, Daniel Andrade Paes de Lima ${ }^{1}$, Geraldo Lúcio de Faria ${ }^{1}$, Leonardo Barbosa Godefroid ${ }^{1}$, \\ Luiz Cláudio Cândido ${ }^{1}$ \\ 1 Universidade Federal de Ouro Preto - UFOP, REDEMAT, Ouro Preto, MG, Brasil.
}

Recebido: 23 Dez., 2016

Aceito: 08 Maio, 2017

E-mails: rodrigoporcaro@yahoo.com.br (RRP), daniel.paeslima@gmail.com (DAPL), geraldolfaria@yahoo.com.br (GLF), leonardo@demet.em.ufop.br (LBG), candido@em.ufop.br (LCC)
Este é um artigo publicado em acesso aberto (Open Access) sob a licença Creative Commons Attribution Non-Commercial, que permite uso, distribuição e reprodução em qualquer meio, sem restriçōes desde que sem fins comerciais e que 0 trabalho original seja corretamente citado.
Resumo: Trilhos com perfil TR-57 do tipo intermediário foram soldados por centelhamento em um estaleiro brasileiro e passaram por detalhada caracterização mecânica e metalográfica. Os dados quantitativos da caracterização metalográfica e dos ensaios mecânicos foram submetidos a análises de variância (ANOVA). Na metalografia confirmou-se a presença majoritária de perlita, porém há também ferrita proeutetóide na linha central da solda e globulização parcial da cementita em regiões da Zona Termicamente Afetada (ZTA), sobretudo na zona de transformação parcial. O tamanho das colônias perlíticas e o espaçamento interlamelar foram correlacionados à microdureza Vickers em toda a extensão da junta. Ensaios de tração revelaram que o metal base atendeu às especificações da Norma AREMA, no entanto, as juntas soldadas não atenderam e a fratura dos corpos de prova ocorreu na região de menor dureza da ZTA. Os resultados permitem compreender, em detalhes, as consequências do processo de soldagem sobre a estrutura do aço e as variações de propriedades em diversas regiões da junta, com destaque às alterações morfológicas da perlita. Relações com modos de falha anteriormente relatados na literatura científica também são apresentadas.

Palavras-chave: Soldagem por centelhamento; Trilhos ferroviários; Propriedades mecânicas de juntas soldadas; Metalurgia da soldagem.

\section{Microstructure and Mechanical Properties of Rail Steel Welded by Flash Butt Welding}

\begin{abstract}
TR-57 intermediate steel rails were welded in a Brazilian flash butt welding plant and the joints were subjected to a detailed mechanical and structural characterization. Quantitative data were subjected to ANOVA analysis. The metallography has confirmed the majority presence of pearlite, but pro-eutectoid ferrite was also verified in the weld centerline. Globulized cementite appeared in some regions of the Heat Affected Zone (HAZ), particularly in the partial transformation zone. The pearlite colony size and pearlite interlamellar spacing were related to Vickers microhardness over the full joint length. The base metal met the minimum specified tensile properties in the AREMA standard. However, the weld joints did not meet the minimum tensile strength and all samples fractured in the partial transformation zone, which has lower hardness. The results help to deep understand the structure-properties relationships over the full joint, highlighting the relations between the welding process and the resultant pearlite morphology. Considerations about the component failure modes previously related in scientific literature are also presented.
\end{abstract}

Key-words: Flash butt welding; Rail steels; Mechanical properties of welded joints; Welding metallurgy.

\section{Introdução}

A substituição de uniões mecânicas do tipo tala-parafusos por soldagem na construção de linhas férreas é uma realidade em todo o mundo, destacando-se a soldagem por centelhamento (flash butt welding) como a principal [1]. O uso de soldagem permite melhorar o comportamento dinâmico dos trilhos na passagem das composições, além de aumentar a capacidade do sistema por permitir maiores velocidades e maiores cargas por eixo nos vagões [1,2]. Mansouri e Monshi [2] também afirmam que juntas soldadas geralmente possuem menor custo, maior produtividade na montagem das linhas ferroviárias e permitem reduzir os impactos e vibrações observados em juntas parafusadas, contribuindo para reduzir a ocorrência de alguns modos de falhas associados à fadiga e à concentração de tensão nos furos de fixação de parafusos. 
A soldagem de trilhos pode ser realizada de dois modos principais: (i) soldagem por centelhamento em máquina estacionária ou móvel, chamada de processo flash butt welding, (ii) soldagem por aluminotermia, um processo de soldagem-fundição que geralmente é realizado em campo. Estima-se que o primeiro responde por cerca de $90 \%$ da soldagem em trilhos longos soldados no mundo [1]. Trata-se de um processo de união no estado sólido que emprega a resistência à passagem de corrente elétrica entre as duas superfícies dos trilhos para promover pré-aquecimento e fusão superficial. Uma vez atingida a temperatura de forjamento, aplica-se pressão que expulsa os líquidos formados e os óxidos, o que produz uma solda com qualidade geralmente superior àquela obtida por aluminotermia [2-4].

Cannon et al. [5] reportam que os trilhos ferroviários, quando em serviço, estão frequentemente submetidos a elevadas tensões, desgaste mecânico, variações climáticas, danos resultantes do contato roda-trilho e até mesmo corrosão. A combinação de dois, ou mais destes fatores, pode resultar na fratura dos mesmos. A falha pode causar catastróficos descarrilamentos de veículos, cujas consequências podem incluir morte, lesões, custos e perda da confiança do público.

Em trabalhos publicados anteriormente [6,7], análises de falhas recorrentes em trilhos ferroviários brasileiros são apresentadas. Estes trabalhos concluem que a principal causa das falhas em serviço é a nucleação de trincas por fadiga na região de concentradores de tensão da junta soldada. Estas trincas crescem estavelmente até atingirem seu tamanho crítico e levam o material ao colapso catastrófico, haja visto o comportamento frágil do aço. Alguns autores [2] mostraram que a microestrutura da junta soldada por centelhamento em trilhos perlíticos consiste em três regiões, sendo a primeira a região de crescimento de grão, a segunda corresponde à região de grãos recristalizados e a terceira é uma região parcialmente transformada. É consenso na literatura que a soldagem por centelhamento resulta em microestrutura perlítica em toda a extensão da Zona Termicamente Afetada (ZTA) de trilhos ferroviários, no entanto, a morfologia perlítica varia significativamente em função do ciclo térmico e das recristalizações decorrentes do processo de soldagem [2-8]. As alterações na morfologia da perlita produzem uma significativa queda da dureza na região de transformação parcial da ZTA, o que, por sua vez, reduz a resistência ao desgaste em regiões específicas do boleto do trilho e pode contribuir para falhas $[4,6,7]$.

Tawfik et al. [8] afirmam que o campo de tensões residuais decorrente do processo de soldagem contribui para a nucleação e propagação de trincas por fadiga em trilhos. Durante o resfriamento da junta soldada, a contração da alma é maior do que a contração do boleto e do patim. Consequentemente, as tensões residuais na alma são trativas e compressivas nas outras regiões [2]. Godefroid et al. [6] mostraram que o mau acabamento superficial na região da alma de juntas soldados por centelhamento contribuem para a nucleação de trincas por fadiga. Mutton [9] indica o esmerilhamento completo da região da alma em trilhos soldados por centelhamento como medida para aumentar a vida em fadiga dos componentes.

Neste trabalho, juntas soldadas por centelhamento de trilhos ferroviários do tipo intermediário passaram por detalhada caracterização estrutural e mecânica com objetivo de compreender os efeitos da soldagem do material e suas relações com as falhas observadas neste tipo de junta.

\section{Materiais e Métodos}

O material utilizado no estudo é um aço para trilhos ferroviários do tipo intermediário que atende à Norma AREMA [10] com perfil TR-57, ou seja, com densidade linear de aproximadamente $57 \mathrm{~kg} / \mathrm{m}$. As especificações de propriedades mecânicas para os trilhos do tipo intermediário são apresentadas na Tabela 1. Os trilhos são importados e foram soldados pelo processo flash butt welding em um estaleiro brasileiro segundo os procedimentos padrão para ferrovias de baixa/média carga por eixo. As juntas não sofreram resfriamento acelerado após a soldagem, sendo resfriadas naturalmente ao ar. Foram amostradas 4 juntas com $800 \mathrm{~mm}$ de comprimento após a etapa de acabamento no estaleiro, todas as amostras seguiram os mesmos parâmetros de soldagem (Tabela 2) e correspondem a um lote único de material.

O metal base foi submetido à análise química por espectrometria de emissão óptica.

Para a caracterização metalográfica do metal base e das juntas soldadas foram aplicadas as técnicas de macrografia e micrografia (vista desarmada e microscopia óptica). A preparação de amostras metalográficas seguiu os procedimentos usuais e o ataque químico foi feito com o reativo Nital na concentração de $2 \%$, segundo 
Tabela 1. Especificações de propriedades mecânicas para trilhos intermediários [10].

\begin{tabular}{lc}
\hline \multicolumn{1}{c}{ Propriedade } & Valor mínimo requerido \\
Dureza superficial [HB] & 325 \\
Limite de escoamento [MPa] & 551 \\
Limite de resistência [MPa] & 1013 \\
Alongamento [\%] & 10 \\
\hline
\end{tabular}

Tabela 2. Parâmetros de soldagem controlados para o trilho intermediário TR-57.

\begin{tabular}{lcc}
\hline \multicolumn{1}{c}{ Parâmetro controlado na soldagem } & Valores \\
Intensidade e duração do flash inicial & $77,4 \mathrm{kA}$ & $20 \mathrm{~s}$ \\
Número de pulsos de corrente de pré-aquecimento e duração dos pulsos & $10 \mathrm{un}$. & $3,8 \mathrm{~s}$ \\
Intensidade dos pulsos de pré-aquecimento & $45-70 \mathrm{kA}$ & - \\
Intensidade da força durante os pulsos de pré-aquecimento & $106 \mathrm{kN}$ & - \\
Intensidade e duração do flash final & $38,3 \mathrm{kA}$ & $14,4 \mathrm{~s}$ \\
Intensidade da força de recalque & $477 \mathrm{kN}$ & - \\
Curso total após recalque & $37-45 \mathrm{~mm}$ & - \\
\hline
\end{tabular}

os planos de corte ilustrados na Figura 1. Ataque com reativo de iodo foi aplicado nas seções (c) e (d) da Figura 1 para revelar as linhas de deformação oriundas da soldagem.

Com a finalidade de se medir a largura da ZTA e compará-la entre as três regiões que compõem o trilho (boleto, alma e patim), foi realizado ataque com Nital $2 \%$ na seção macrográfica (a) na Figura 1. Para se analisar a microestrutura e medir o espaçamento interlamelar perlítico em Microscópio Eletrônico de Varredura (MEV), a seção representada por (b) na Figura 1 foi atacada com Nital 2\%, a 10mm abaixo da superfície do boleto, para evitar a região endurecida devido ao resfriamento acelerado aplicado na fabricação dos trilhos. As medições de espaçamento interlamelar foram executadas em quatro diferentes regiões, que foram: a $2 \mathrm{~mm}$ da linha central da solda, que corresponde à região de crescimento de grão; a $8 \mathrm{~mm}$ da linha central, região de refino de grão; a $10 \mathrm{~mm}$ da linha central, região de transformação parcial; finalmente, a $18 \mathrm{~mm}$ da linha central, no metal base. O espaçamento interlamelar foi obtido a partir de medições realizadas em 20 campos distintos registrados em MEV com ampliação original de 20.000 vezes em cada região. Em cada campo, com auxílio do software imageJ, traçou-se linhas perpendiculares às lamelas de perlita e o número de lamelas de cementita interceptados por unidade de comprimento foi determinado para a obtenção da média de espaçamento. Os campos para as medidas foram aqueles que apresentaram, para cada posição de interesse, o menor espaçamento interlamelar, o que garante, segundo Krauss [11], que o plano de corte metalográfico foi perpendicular às lamelas.

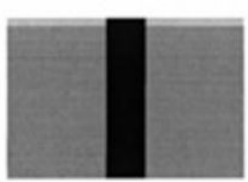

a)

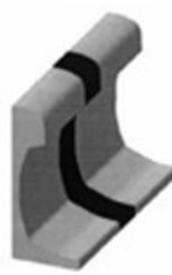

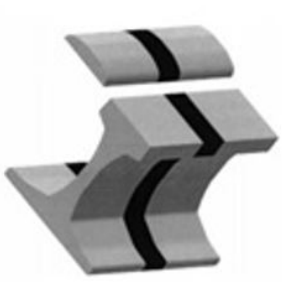

b)

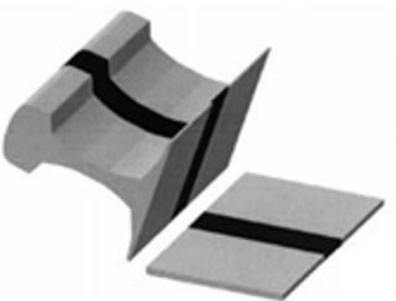

c)

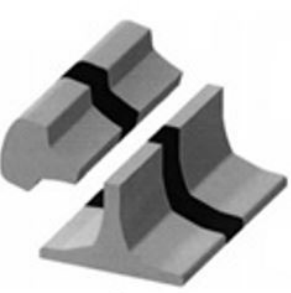

d)

Figura 1. Representação esquemática das seções de corte para caracterização estrutural das juntas soldadas. (a) seção completa da junta; (b) seção no boleto a $10 \mathrm{~mm}$ da superfície; (c) seção no patim dos trilhos; (d) seção na alma dos trilhos. Adaptado de Mansouri e Monshi [2]. 
Para se medir o tamanho das colônias perlíticas, amostras do boleto soldado foram tratadas em forno com atmosfera controlada do Laboratório de Tratamentos Térmicos e Microscopia óptica (LTM/UFOP) até que a temperatura atingisse $700^{\circ} \mathrm{C}$ (baixa pressão parcial de oxigênio). Depois de atingida a temperatura, as amostras permaneceram 10 minutos dentro do forno, o que correspondeu a um ataque térmico por oxidação preferencial sem austenitização. Foram obtidas cinco imagens de cada campo de interesse para a medida do tamanho das colônias perlíticas em três regiões, que foram: a $2 \mathrm{~mm}$ da linha central (crescimento de grão), a $8 \mathrm{~mm}$ da linha central (refino de grão) e no metal base. As imagens foram processadas pelo software LAZ, Leica versão 4.6, segundo a Norma ASTM E1382 [12].

Traçou-se um perfil de microdureza Vickers na seção (b) da Figura 1a 10mm abaixo da superfície do boleto, com carga de $100 \mathrm{gf}$ por $10 \mathrm{~s}$, com espaçamento entre indentações de $0,5 \mathrm{~mm}$, de forma a abranger todas as regiões da junta: metal base, transformação parcial, refino de grão, crescimento de grão e linha central.

Para os ensaios de tração foram empregados corpos de prova recomendados pela Norma ASTM E8M [13] (Figura 2). Foram utilizados seis corpos de prova, três do metal base e três de juntas. A região útil utilizada foi maior que a largura total da ZTA (cerca de $32 \mathrm{~mm}$ ). Todos os corpos de prova foram usinados a partir de boletos, no sentido longitudinal e a $10 \mathrm{~mm}$ abaixo da superfície.

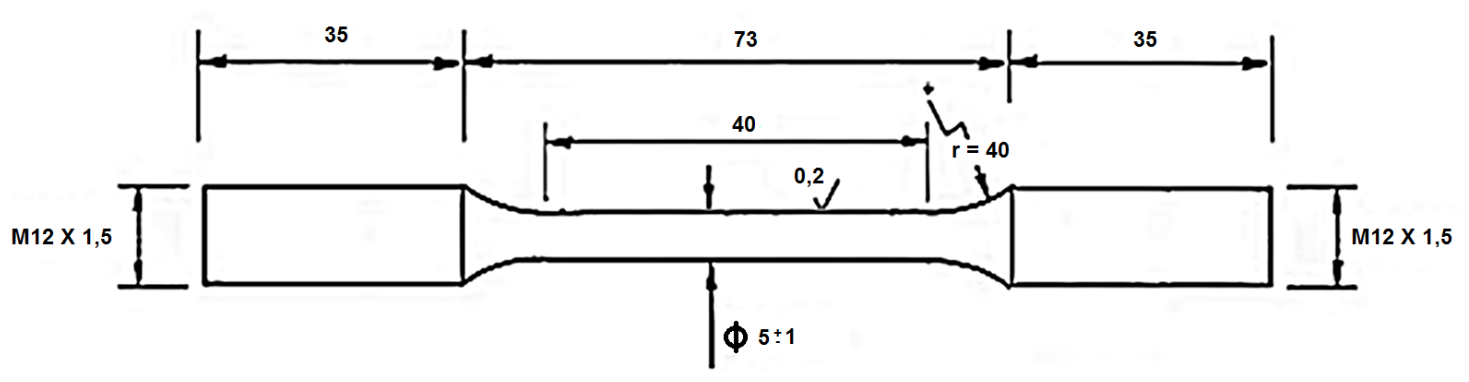

Figura 2. Dimensões em milímetros dos corpos de prova para os ensaios de tração do metal base e das juntas soldadas de trilhos ferroviários.

Para todos os resultados quantitativos obtidos na caracterização estrutural (tamanho de colônias perlíticas e espaçamento interlamelar) e na caracterização mecânica (resultados dos ensaios de tração), realizaram-se análises de variância (ANOVA). Além disso, testes t de Student foram realizados nos dados aos pares para verificar, com $95 \%$ de confiança, se as médias eram diferentes. As análises foram realizadas no software Microsoft Excel e os testes $t$ de Student foram precedidos de testes $F$ para verificar se as variâncias das amostras eram iguais ou diferentes.

\section{Resultados e Discussão}

\subsection{Análise química e macrografia}

Os resultados da análise química são apresentados na Tabela 3. As amostras de metal base atenderam às faixas especificadas pela norma AREMA [10].

Em função do teor de carbono relativamente baixo do aço, esperava-se uma maior relação C-Mn, uma vez que o manganês tem como característica a expansão do campo austenítico, com diminuição da composição eutetóide e da temperatura eutetóide, reduzindo a formação de ferrita proeutetóide [14]. Em função do teor de

Tabela 3. Composição química do metal base.

\begin{tabular}{cccccccccccc}
\hline & \multicolumn{11}{c}{ Elemento (\% em massa) } \\
\cline { 2 - 13 } & $\mathbf{C}$ & Mn & Si & $\mathbf{P}$ & $\mathbf{S}$ & $\mathbf{C r}$ & $\mathbf{M o}$ & $\mathbf{N i}$ & $\mathbf{V}$ & $\mathbf{N b}$ \\
Média & 0,715 & 0,843 & 0,240 & 0,016 & 0,008 & 0,078 & 0,009 & 0,012 & 0,002 & 0,004 \\
\hline
\end{tabular}


Mn relativamente baixo, uma pequena fração de ferrita proeutetóide foi observada no metal base, conforme será apresentado posteriormente.

O resultado do ataque macrográfico nas seções de juntas soldadas é apresentado na Figura 3 e a largura da ZTA nas três regiões é apresentada na Figura 4.

As camadas superficiais do trilho transferem corrente elétrica mais facilmente quando comparadas ao volume (efeito superficial). Portanto, os três pontos mais próximos à superfície do boleto na Figura 4 não representam o perfil da largura da ZTA do boleto, uma vez que a densidade de corrente na superfície é maior do que a densidade de corrente no interior, fazendo com que o aporte de calor e, em consequência, a largura da região próxima à superfície seja maior.
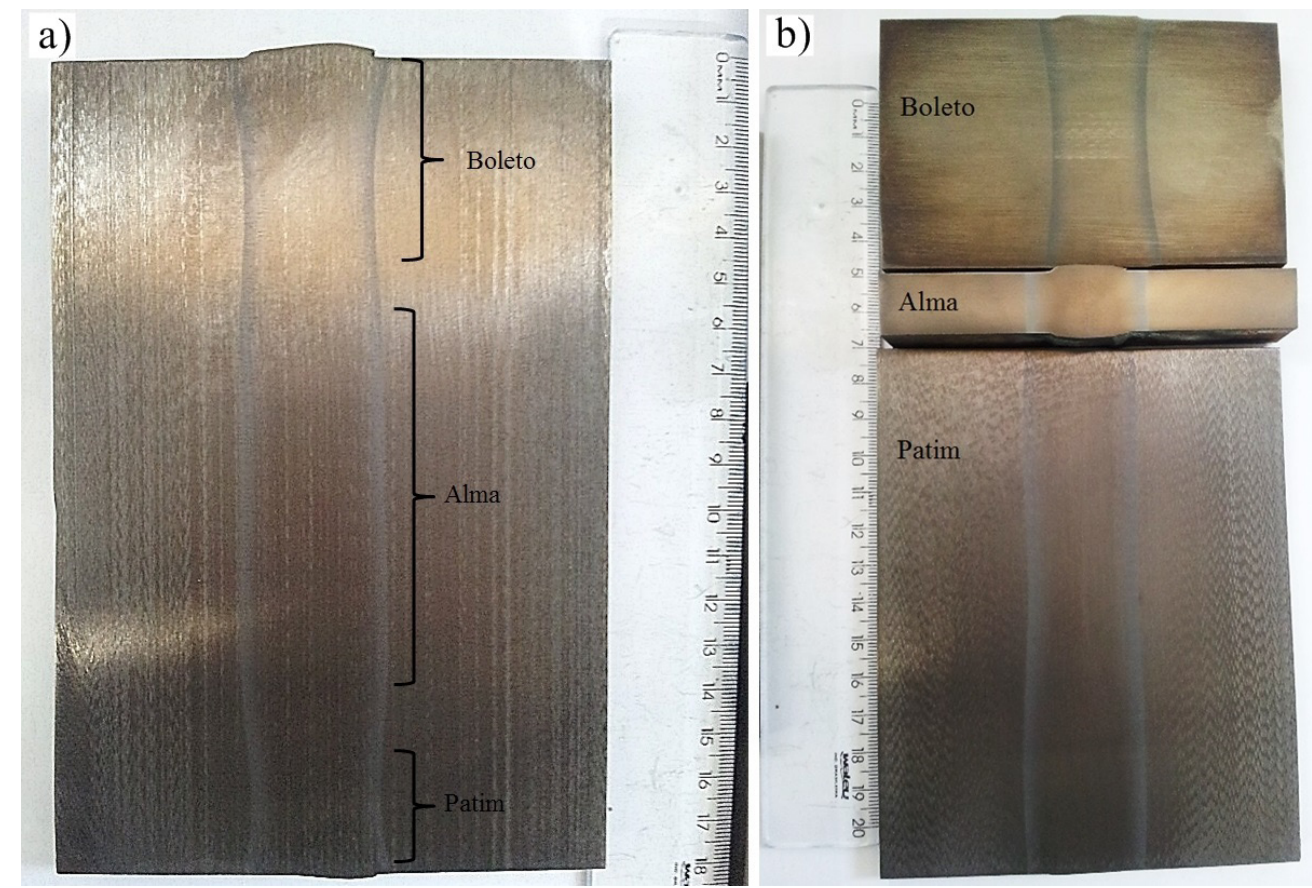

Figura 3. Macrografias de juntas soldadas atacadas com Nital 2\%; (a) Corte representado por (a) na Figura 1; (b) Cortes representados por (b)-boleto, (c)-patim e (d)-alma na Figura 1.

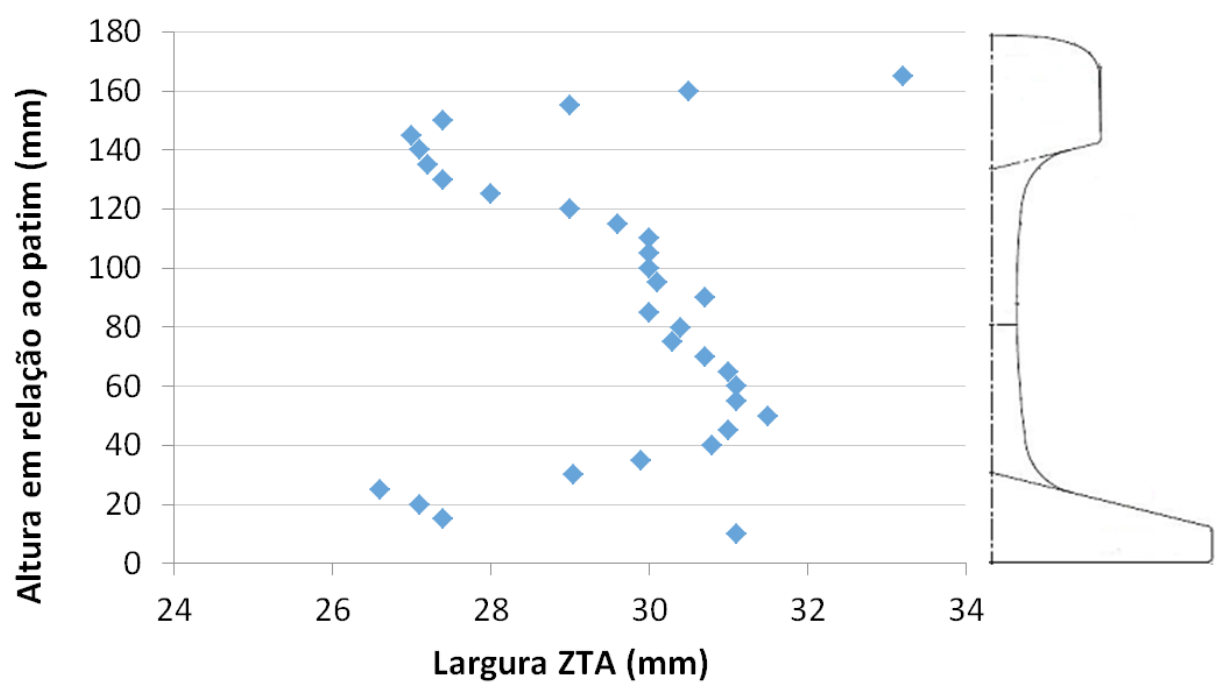

Figura 4. Variação da largura da ZTA nas regiões do trilho ferroviário soldado. 
Das três regiões que compõem o trilho, a alma é a que possui a menor espessura. Por isso, a densidade de corrente que passa por unidade de área nesta região é maior do que nas demais, o que resulta em um maior aporte térmico por unidade de área [2]. Esta maior densidade de corrente é responsável pela ZTA da alma ser maior do que a das outras regiões. Outros autores [2] reportaram que a largura da ZTA na alma é maior dentre as três regiões de trilhos soldados por centelhamento elétrico, no entanto, não apresentaram medidas comparativas.

Conforme comentado anteriormente, as maiores temperaturas de pico observadas na alma durante o processo de soldagem causam uma maior contração desta região durante o resfriamento, resultando no desenvolvimento de tensões residuais trativas [2,8,9]. Além disso, a superfície da alma pode conter concentradores de tensão resultantes do corte de rebarba posterior à soldagem dos trilhos que, associado às tensões residuais e ao carregamento em serviço, pode contribuir para o trincamento por fadiga [6-9]. A Figura 5a apresenta uma fotografia de microscópio óptico de um concentrador de tensão resultante da falta de esmerilhamento da rebarba de soldagem na região da alma das amostras.

Além do concentrador de tensão devido ao acabamento inadequado, podem existir descontinuidades de soldagem, como porosidades, trincas, entre outros [1,2,4,9]. No presente trabalho, tais descontinuidades não foram observadas. Em função do efeito deletério do concentrador de tensão mostrado (Figura 5a) em análises de falhas reportadas na literatura $[6,7]$ e, considerando a prática atual dos estaleiros de soldagem brasileiros que apenas removem as rebarbas das superfícies do boleto e patim, recomenda-se o esmerilhamento também da alma como uma medida preventiva para retardar a nucleação de trincas por fadiga nos trilhos soldados por centelhamento.

O resultado do ataque com reativo de iodo na região central do boleto e na alma pode ser observado na Figura 5b. A comparação entre a largura da ZTA no centro do boleto (amostra superior) e da alma (amostra inferior) corrobora o que foi observado com o ataque Nital, ou seja, maior a largura da ZTA na alma. O ataque com reativo de iodo revelou o padrão de deformação devido à aplicação de pressão no final do processo de soldagem e ao corte de rebarba na alma do trilho. Observa-se que a deformação na alma foi maior que no boleto, função também do maior aporte térmico e, portanto, maior expansão térmica durante o aquecimento nesta região.

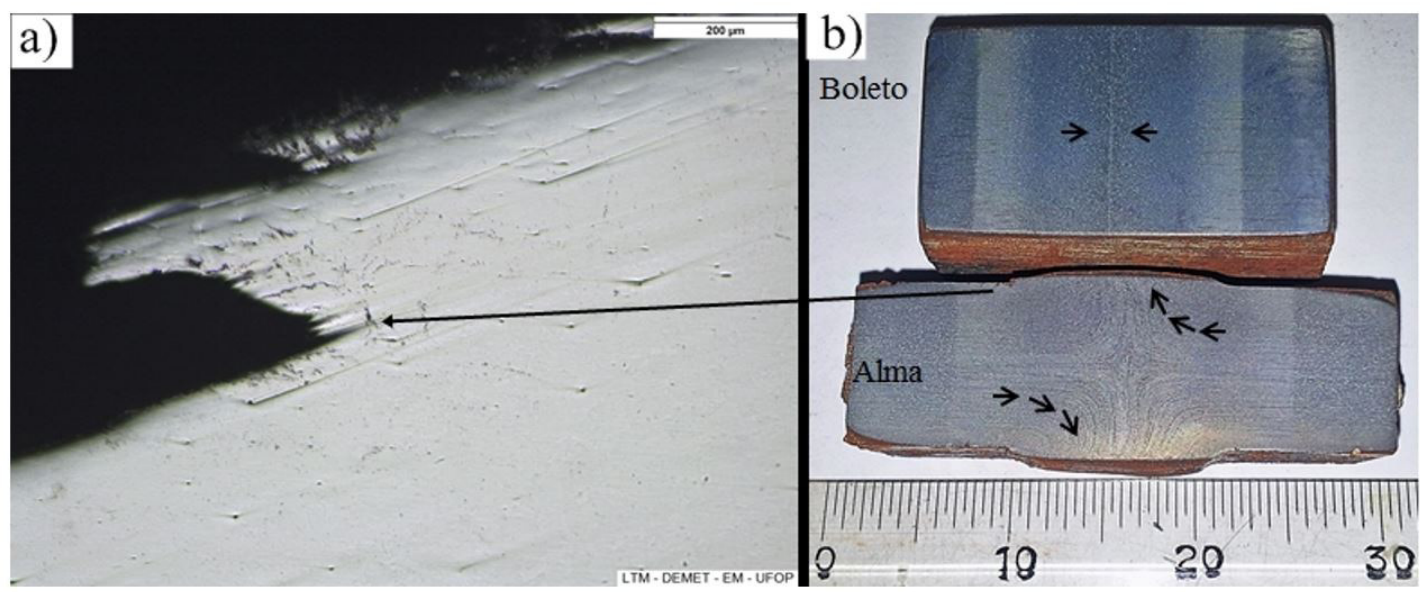

Figura 5. Concentrador de tensão na alma do trilho gerado pelo corte de rebarba (sem ataque) (a). Linhas de deformação resultantes do processo de soldagem na alma e no boleto de trilho (reativo de iodo) (b).

\subsection{Micrografia}

Todas as seções de corte apresentadas na Figura 1 apresentaram constituintes equivalentes e microestruturas semelhantes, com a identificação das três regiões que constituem a ZTA (transformação parcial, refino de grão e crescimento de grão), as principais diferenças observadas foram nas extensões de cada uma das regiões em função do aporte térmico. Por uma questão de espaço e síntese, apenas os resultados obtidos na caracterização da região central do boleto são apresentados, uma vez que é a região que apresenta maior homogeneidade na estrutura e onde ocorre o contato roda-trilho, portanto, as variações microestruturais podem ter consequências diretas no desempenho do componente [4]. 
A análise metalográfica confirmou que o metal base apresenta-se majoritariamente perlítico, no entanto, ferrita livre (proeutetóide) também foi observada, destaque na Figura 6a. Na Figura 6 é possível observar as três principais regiões que constituem a ZTA, sendo a região de transformação parcial (Figura 6b), a região de refino de grão (Figura 6c) e a de crescimento de grão (Figura 6d), em comparação ao metal base. Na Figura 7 apresenta-se um esquema de todas as regiões.

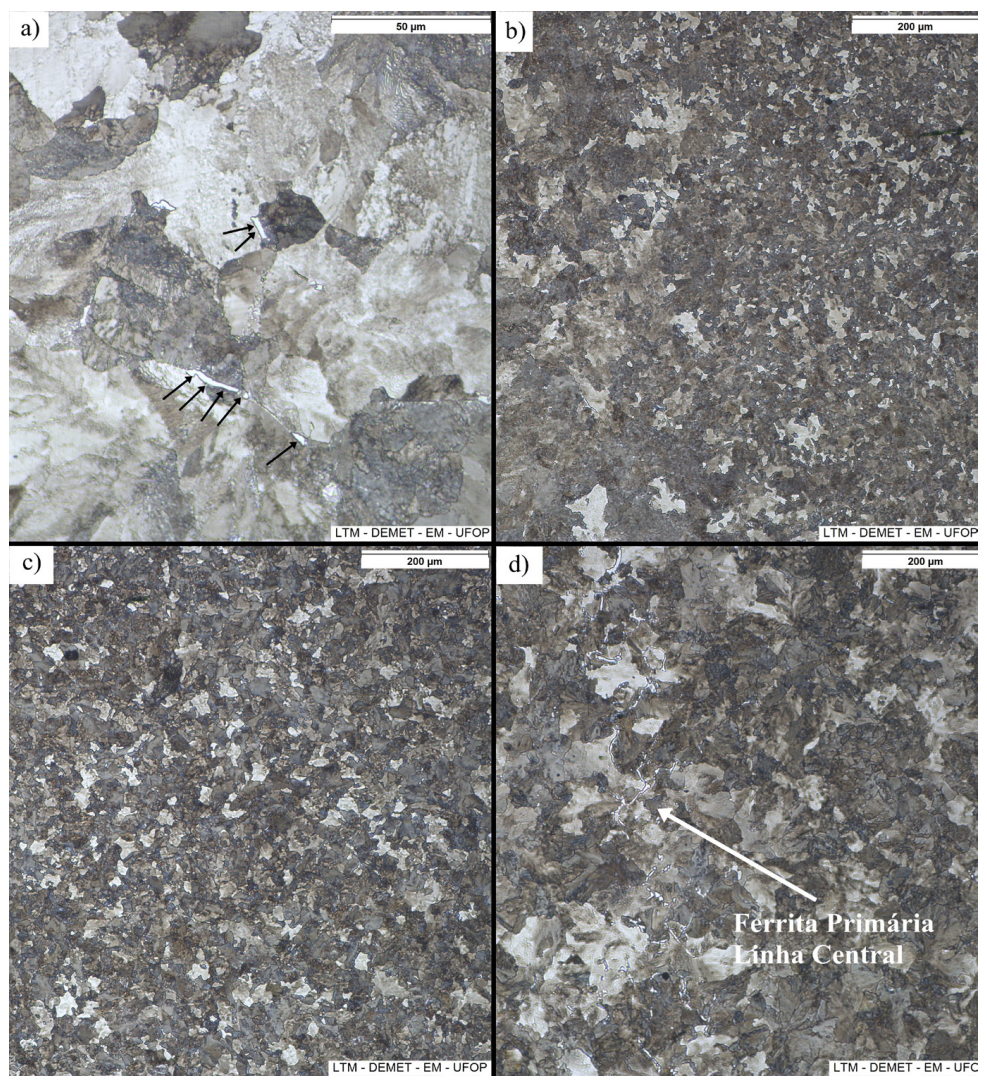

Figura 6. Micrografia de junta soldada de trilho intermediário atacado com Nital $2 \%$, centro do boleto, $10 \mathrm{~mm}$ abaixo da superfície. (a) Metal Base; (b) MB/Refino de Grão; (c) Refino de Grão; (d) Crescimento de grão com linha central descarbonetada. Aumento de original de 500x (a) e 100x (b, c e d).

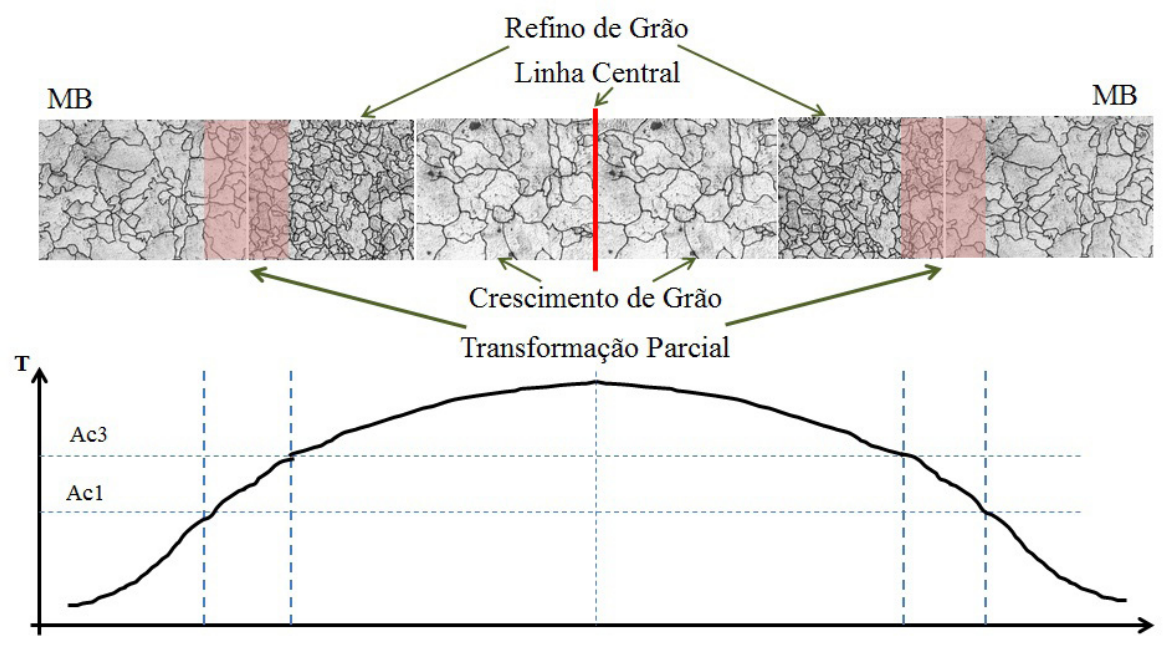

Figura 7. Figura esquemática relacionando a temperatura de pico e as diversas microestruturas das regiões da junta. 
Segundo Mansouri e Monshi [2], ocorre recristalização dinâmica na ZTA ao final da soldagem por centelhamento, uma vez que o processo envolve deformação. A região de crescimento de grão corresponde àquela que possui temperatura de pico suficiente para promover o crescimento de grão austenítico após a recristalização, tal crescimento diminui à medida que se afasta da linha central até que uma região de grãos austeníticos recristalizados dá origem à perlita mais refinada, zona de refino de grão na Figura 6c e Figura 7. Apesar da soldagem por centelhamento apresentar uma atmosfera levemente redutora [3], ocorreu descarbonetação na linha central, responsável pela formação significativa de ferrita livre, como evidenciado na Figura $6 \mathrm{~d}$. Descarbonetação é comum nesse tipo de processo de soldagem de trilhos e geralmente não representa um problema em função da pequena extensão da região descarbonetada $[4,6,7,15]$.

Foi realizada também uma avaliação de inclusões na região central do boleto e na alma, a partir de amostras polidas e sem ataque, como ilustrado na Figura 8. Pode-se observar que o material apresenta inclusões alongadas com aspecto típico de sulfetos de manganês, o que foi confirmado por MEV/EDS (Figura 8c). Outra observação que merece destaque é a direção das inclusões na Figura 8, alongadas em paralelo ao sentido de laminação do trilho em (a) e realinhadas em (b) devido à deformação a quente no final do processo de soldagem.

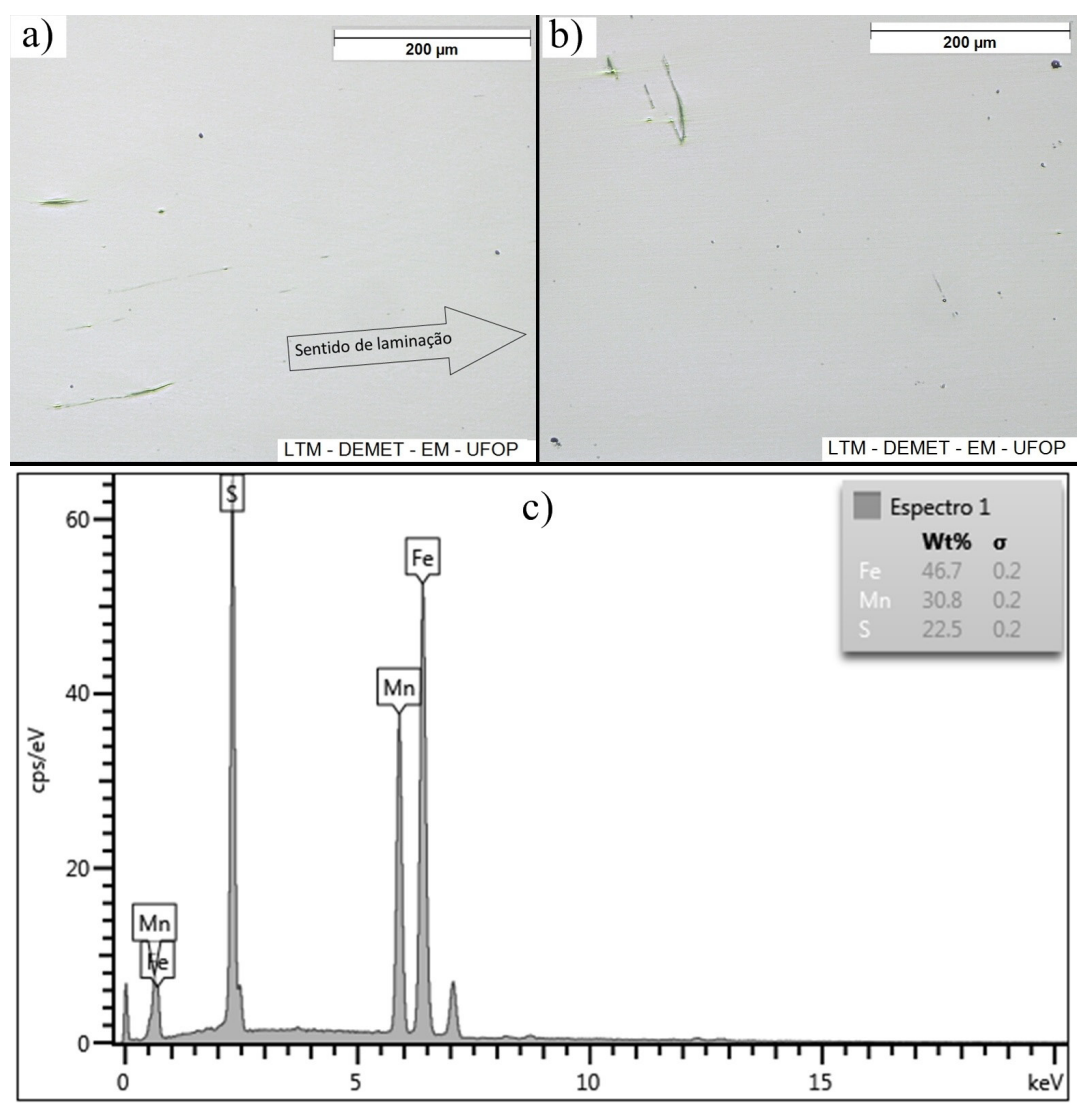

Figura 8. Análise de inclusões no metal base com inclusões alinhadas no sentido de laminação (a) e na junta soldada com realinhamento das inclusões devido à deformação no final da soldagem (b), região central da alma, sem ataque. Aumento original de 100x. (c) Espectro obtido por MEV/EDS em inclusões de sulfeto de manganês.

A Figura 9a ilustra a microestrutura da região de refino de grão com as colônias de perlita coloridas pelo software de análise após ataque térmico para revelar os contornos. A Figura $9 \mathrm{~b}$ retrata a relação entre as cores das colônias com a distribuição dos seus tamanhos, segundo o número de grão ASTM. A mesma análise foi realizada no metal base e na região de crescimento de grão, os resultados são apresentados na forma de diâmetro circular equivalente na Tabela 4. As análises de variância indicaram que os dados obtidos possuem médias diferentes para as três regiões, além disso, testes t de Student realizados nos dados aos pares indicaram, com 95\% de confiança, que tratam-se de médias diferentes, com $p<0,05$. 
a)

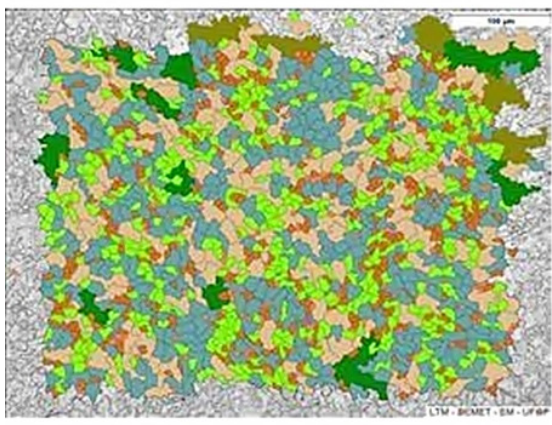

b)

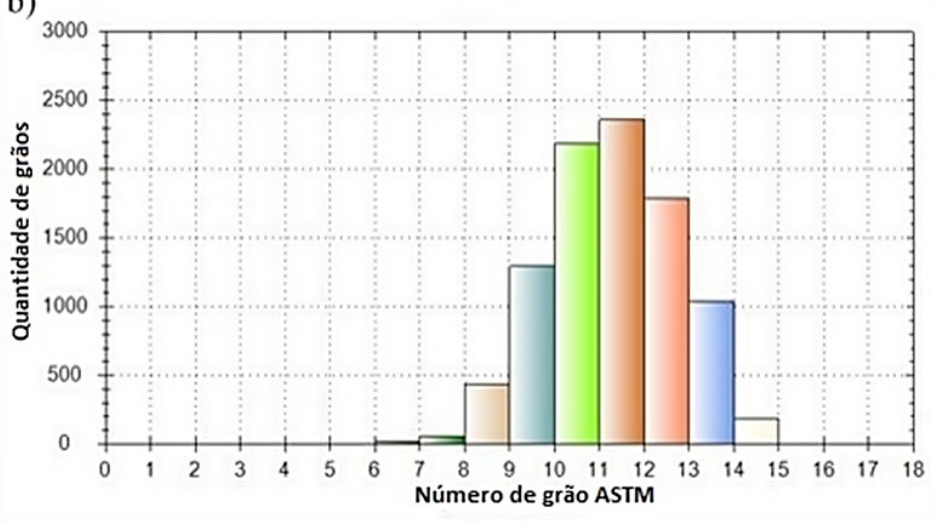

Figura 9. Microestrutura da região de refino de grão evidenciando-se o tamanho dos grãos por diferentes colorações (a), 200x. Distribuição de frequência dos tamanhos de colônias de perlita (número de grão ASTM) na região de refino de grão de um aço de trilho intermediário soldado por centelhamento (b), região do boleto a $10 \mathrm{~mm}$ abaixo da superfície.

Tabela 4. Medidas de tamanho médio de colônias perlíticas na região central do boleto em junta soldada, 10mm abaixo da superfície.

\begin{tabular}{lccc}
\hline \multirow{2}{*}{$\begin{array}{c}\text { Tamanho de grão (diâmetro } \\
\text { circular equivalente } \boldsymbol{\mu m} \text { ) }\end{array}$} & \multicolumn{3}{c}{ Região da Junta (distância à linha central) } \\
\cline { 2 - 4 } Média & $\mathbf{C G}$ - $\mathbf{2 m m}$ & RG - 8mm & MB - 16mm \\
Desvio Padrão & 44,9 & 9,2 & 17,4 \\
\hline
\end{tabular}

CG: crescimento de grão; RG: refino de grão; MB: metal base.

Mansouri e Monshi [2] reportaram números de grão ASTM variando de 1 (254 $\mu$ m de diâmetro equivalente), para regiões mais próximas à linha central, até $5(63,5 \mu \mathrm{m})$ conforme aumentava-se a distância da linha central na zona de crescimento de grão em juntas de trilhos soldadas por centelhamento em um aço microligado. Para a zona de refino de grão, o número de grão ASTM reportado pelos autores foi aproximadamente $9(15,9 \mu \mathrm{m})$.

Fotomicrografias de MEV da junta soldada são apresentadas na Figura 10, todas a $10 \mathrm{~mm}$ abaixo da superfície do trilho no boleto. As medidas de espaçamento interlamelar perlítico são apresentadas na Tabela 5 e a análise de variância indicou que tratam-se de médias diferentes para as quatro regiões, além disso, testes $t$ de Student realizados aos pares indicaram que as médias são diferentes entre todas as regiões, com $p<0,05$. Observa-se na Figura 10a a microestrutura majoritariamente perlítica que constitui o metal base na altura do boleto. Na região de transformação parcial, Figura 10b, é comum a alteração da perlita em função do ciclo térmico do processo de soldagem [7], com globulização parcial da cementita, resultando em redução da dureza local como será posteriormente abordado.

Tabela 5. Medidas de espaçamento interlamelar perlítico na região central do boleto em junta soldada.

\begin{tabular}{lcccc}
\hline \multirow{2}{*}{ Espaçamento $(\boldsymbol{\mu m})$} & \multicolumn{4}{c}{ Região da Junta (distância à linha central) } \\
\cline { 2 - 5 } & CG - 2 $\mathbf{m m}$ & RG - 8mm & RG - 10mm & MB - 16mm \\
Média & 0,17 & 0,20 & 0,24 & 0,15 \\
Desvio Padrão & 0,03 & 0,02 & 0,05 & 0,02 \\
\hline
\end{tabular}

CG: crescimento de grão; RG: refino de grão; MB: metal base. 


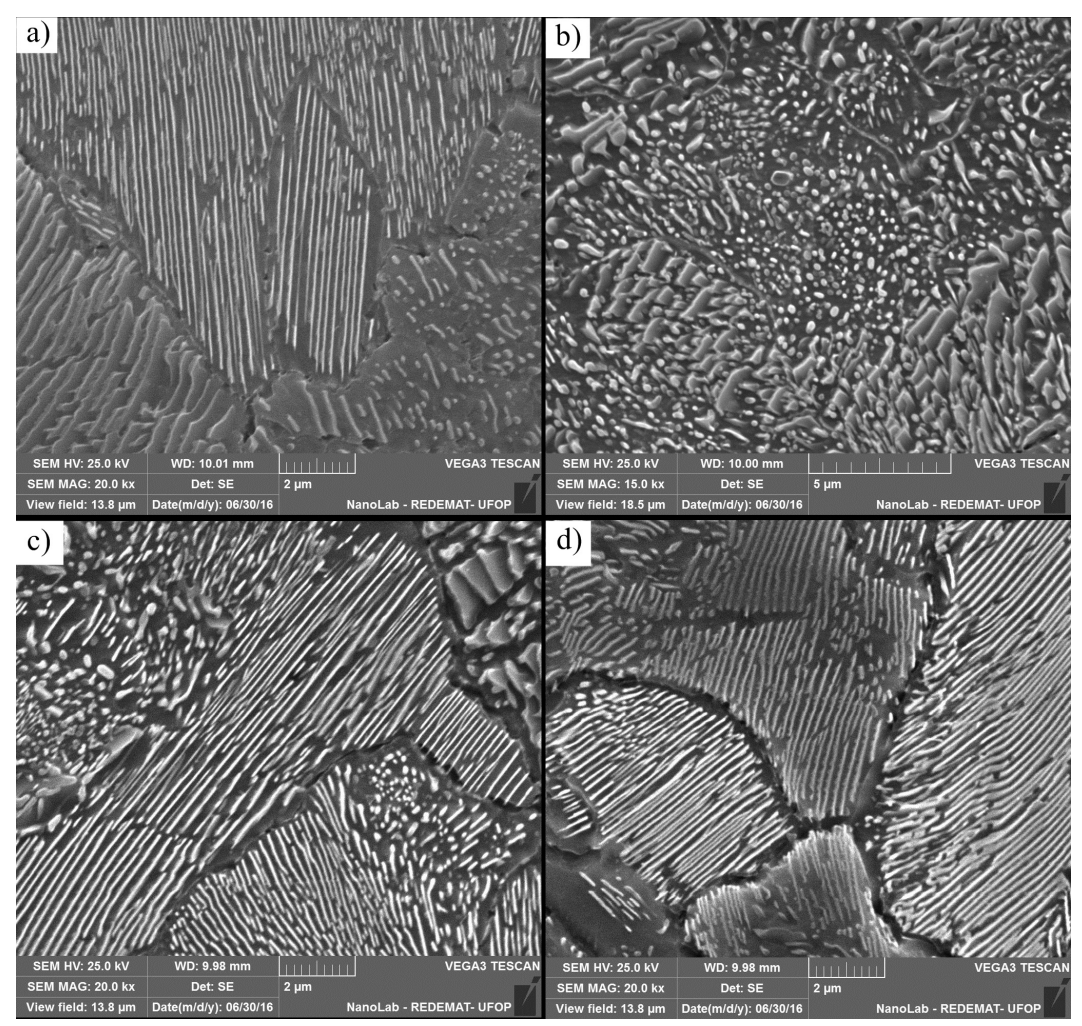

Figura 10. Microestrutura em MEV da junta soldada no centro do boleto, $10 \mathrm{~mm}$ abaixo da superfície. (a) Metal Base, $18 \mathrm{~mm}$ da linha central; (b) Transformação Parcial, $12 \mathrm{~mm}$ da linha central; (c) Refino de Grão, $8 \mathrm{~mm}$ da linha central; (d) Crescimento de grão, $2 \mathrm{~mm}$ da linha central. Aumento original de 20000x (a,b,c) e 15000x (b).

Na região de refino de grão, a mesma estrutura perlítica em lamelas do metal base foi observada, Figura 10c. No entanto, o espaçamento interlamelar encontrado nesta região é maior do que o encontrado para o metal base, Tabela 5. Além disso, foi também observada a modificação da morfologia perlítica, com início de esferoidização, tais alterações aumentam à medida que se aproxima da região de transformação parcial. A zona de crescimento de grão apresentou uma microestrutura mais parecida com a do metal base (Figura 10d), porém com um maior espaçamento interlamelar entre as lamelas de ferrita e cementita.

A modificação da morfologia da perlita em função do ciclo termo-mecânico da soldagem por centelhamento a sua consequente implicação nos valores de dureza (como posteriormente apresentado) é um dos grandes desafios tecnológicos para os fabricantes de trilhos e para as ferrovias [16]. Ressalta-se também o conhecimento restrito sobre os mecanismos cinéticos que controlam a esferoidização da cementita na região de transformação parcial $[4,15,16]$ e bem como a modificação do espaçamento interlamelar nas diversas regiões das juntas soldadas de aços perlíticos para trilhos.

A partir da análise da Tabela 5 e dos valores de tamanho das colônias perlíticas (Tabela 4), pode-se concluir que a região próxima à linha central apresentou maior tamanho de grão que o metal base e que a região de refino de grão. No entanto, a região de crescimento de grão possui espaçamento interlamelar perlítico menor que aquele medido na região de refino de grão. Tal fato poderia ser justificado devido à maior temperabilidade na região de grãos grosseiros [17], o que deslocaria a curva de transformação em resfriamento contínuo (diagrama TRC) e, portanto, a transformação da austenita ocorreria em menor temperatura.

\subsection{Ensaios mecânicos}

Os resultados de microdureza Vickers obtidos no perfil do boleto soldado são apresentados na Figura 11a e são coerentes com as microestruturas obtidas no microscópio óptico e MEV, sendo as zonas de menor dureza equivalentes àquelas onde foram encontradas as maiores alterações na morfologia da perlita. Ressalta-se que a 
dureza da zona de refino de grão apresentou valores mais baixos quando comparados com a dureza da zona de crescimento de grão, esta diferença pode ser explicada devido às variações dos espaçamentos interlamelar e à mudança de morfologia da perlita. Muitos autores têm reportado a queda de dureza em regiões da ZTA de aços perlíticos soldados por centelhamento $[1,2,4,6-9,15,16]$ no entanto, resultados que correlacionem a microdureza com a morfologia perlítica em cada uma das regiões da ZTA não estão disponíveis na literatura.

Moreira [18] mostrou que o espaçamento interlamelar perlítico possui uma relação do tipo Hall-Petch com a dureza. O resultado de ajuste entre os valores médios de dureza e as médias de espaçamento interlamelar para o boleto soldado, segundo a relação de Hall-Petch, pode ser observado na Figura $11 b$. O valor do coeficiente de ajuste linear indica forte correlação ente os dados.

Os resultados dos ensaios de tração são apresentados na Tabela 6, na qual MB corresponde a corpos de prova do metal base e $\mathrm{S}$ a corpos de prova com soldas. Os valores de limite de escoamento, limite de resistência e alongamento do metal base atenderam ao mínimo especificado para o aço intermediário segundo a Norma AREMA [10]. No caso das juntas soldadas, observou-se redução no limite de escoamento e limite de resistência, as diferenças foram significativas em testes t de Student, com $\mathrm{p}<0,05$. A variação de alongamento percentual, por sua vez, não pôde ser considerada diferente com 95\% de confiança. Tais resultados são semelhantes aos obtidos por Godefroid et al. [6]. Além disso, todos os corpos de prova soldados fraturaram na região de transformação parcial, entre $10 \mathrm{~mm}$ e $12 \mathrm{~mm}$ da linha central.
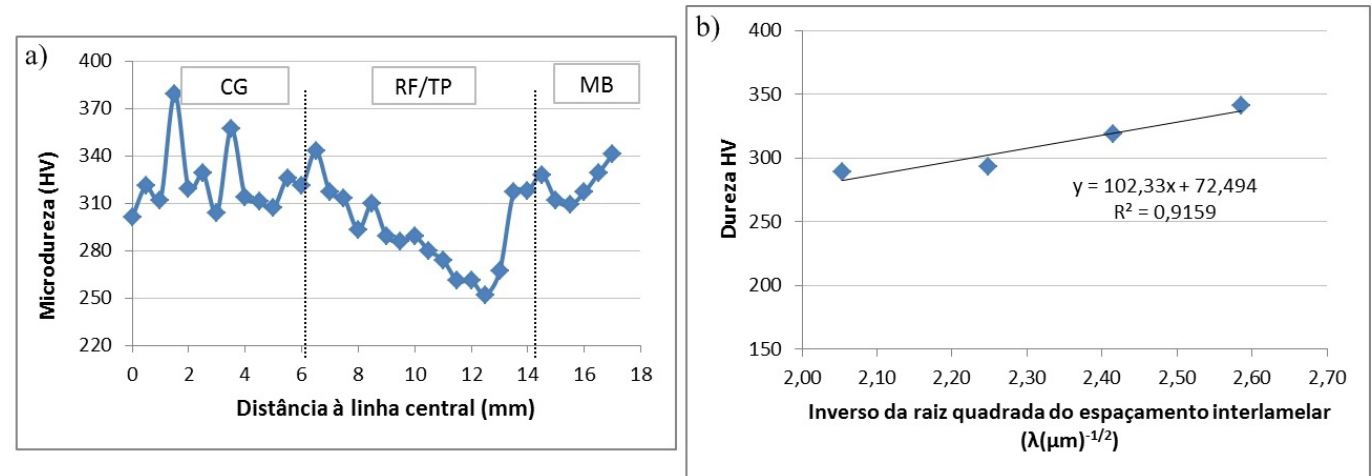

Figura 11. Perfil de microdureza Vickers de junta soldada no boleto do trilho, $10 \mathrm{~mm}$ abaixo da superfície. CG - Crescimento de Grão; RF - Recristalizada com Refino de grão; TP - Transformação Parcial; MB - Metal Base (a). Ajuste entre os valores de microdureza e a média de espaçamento interlamelar perlítico segundo Hall-Petch (b).

Tabela 6. Resultados dos ensaios de tração para o metal base e juntas soldadas. MB corresponde a corpos de prova do metal base e $\mathrm{S}$ a corpos de prova com soldas.

\begin{tabular}{lccc}
\hline \multicolumn{1}{c}{ Corpo de Prova } & Limite de Escoamento (MPa) & Limite de Resistência (MPa) & Alongamento (\%) \\
MB Média & 1069 & 1141 & 8 \\
Desvio padrão & 15 & 28 & 2 \\
S Média & 941 & 957 & 9 \\
Desvio padrão & 22 & 20 & 1 \\
\hline
\end{tabular}

A diminuição do limite de escoamento e do limite de resistência da solda pode ser atribuída às alterações estruturais anteriormente indicadas na metalografia e nos ensaios de dureza, como a globulização parcial da cementita na perlita e o aumento do espaçamento interlamelar.

A presença de uma região parcialmente esferoidizada e a sua relação com a redução da dureza em juntas soldadas por centelhamento foi extensamente discutida em INNOTRACK [15]. Os autores apresentam e uma metodologia para reduzir a largura da ZTA das soldas a partir da adoção de 3 ou 4 pulsos de pré-aquecimento em substituição ao procedimento padrão com 11 pulsos de pré-aquecimento. Os resultados apresentados indicaram uma redução da largura total da ZTA em trilhos $350 \mathrm{HT} / 60 \mathrm{E} 1$ de $37 \mathrm{~mm}$ para $27 \mathrm{~mm}$ na superfície do boleto. No entanto, não foi 
discutido pelos autores a influência da mudança de procedimento de soldagem na microestrutura, espaçamento interlamelar perlítico e tensões residuais da junta, além disso, os procedimentos sugeridos alteraram pouco os valores mínimos de dureza observados na ZTA.

\section{Conclusões}

- A largura da ZTA varia entre as regiões que compõem o trilho ferroviário, sendo a alma a região de maior largura da ZTA;

- As alterações microestruturais nas zonas de refino de grão e transformação parcial provenientes da soldagem, principalmente a globulização parcial da cementita e o maior espaçamento interlamelar perlítico, reduziram de forma significativa a dureza nestas regiões e resultaram em uma redução na resistência mecânica em tração;

- Apesar do maior tamanho de grão das colônias de perlita na região de crescimento de grão, o espaçamento interlamelar perlítico foi menor que aquele medido na região de refino de grão;

- A mudança da morfologia da perlita (globulização) não se restringiu à zona de transformação parcial da ZTA, sendo observado também na zona de refino de grão;

- Apesar de o metal base atender às especificações de propriedades mecânicas para trilhos intermediários da Norma AREMA, as juntas soldadas não atenderam e a fratura em tração sempre ocorreu na região de maior globulização da cementita.

\section{Agradecimentos}

À Empresa VLI-FCA por ceder gentilmente as amostras e ao laboratório de microscopia eletrônica NanoLab - Redemat.

\section{Referências}

[1] Farhangi H, Mousavizadeh SM. Horizontal split-web fractures of flash butt welded rails. In: Proceedings of the 8th International Fracture Conference; 2007; Istanbul, Turquia. Istanbul: Yildiz Technical University; 2007. p. 509-517.

[2] Mansouri $\mathrm{H}$, Monshi A. Microstructure and residual stress variations in weld zone fo flash-butt welded railroads. Science and Technology of Welding and Joining. 2004;9(3):237-246. http://dx.doi.org/10.1179/136217104225012201.

[3] O’Brien RL, editor. Welding handbook: welding process. 9. ed. Miami: American Welding Society; 2007. (vol. 2).

[4] Micenko P, Muruganant A, Huijun L, Xiaofeng X. Double dip hardness profiles in rail weld heat-affected zone: literature and research review report. Brisbane: CRC for Rail Innovation; 2013. Final Report, Project name: Improvements to Railway Welding.

[5] Cannon DF, Edel K-O, Grassie S, Sawley K. Rail defects: an overview. Fatigue Fract Engineering Mater Structure. 2003;26(10):865887. http://dx.doi.org/10.1046/j.1460-2695.2003.00693.x.

[6] Godefroid LB, Faria GL, Cândido LC, Viana TG. Fatigue failure of a flash butt welded rail. Procedia Materials Science. 2014;3:18961901. http://dx.doi.org/10.1016/j.mspro.2014.06.306.

[7] Godefroid LB, Faria GL, Cândido LC, Viana TG. Failure analysis of recurrent cases of fatigue fracture in flash butt welded rails. Engineering Failure Analysis. 2015;58:407-416. http://dx.doi. org/10.1016/j.engfailanal.2015.05.022.

[8] Tawfik D, Mutton PJ, Chiu WK. Experimental and numerical investigations: alleviating tensile residual stress in flash-butt welds by localized rapid post-weld heat treatment. Journal of Materials Processing Technology. 2008;196(1-3):279-291. http://dx.doi.org/10.1016/j.jmatprotec.2007.05.055.

[9] Mutton P. Fatigue damage in rails and rail welds under high axle load conditions. In: Anais do 11 o Congresso Internacional de Fadiga; 2014; Melbourne. Melbourne: RMIT University; 2014.

[10] American Railway Engineering and Maintenance-of-Way Association. Manual of railway engineering and maintenance of way association. Lanham: AREMA; 2013.

[11] Krauss G. Steels: processing, structure and performance. 3. ed. Ohio: ASM International; 2005.

[12] American Society for Testing and Materials. E1382: standard test methods for determining average grain size using semiautomatic and automatic image analysis. West Conshohocken: ASTM; 2015. 24 p.

[13] American Society for Testing and Materials. E8M: standard test methods for tension testing of metallic materials. West Conshohocken: ASTM; 2008. 22 p.

[14] Faria GL, Godefroid LB, Cândido LC, Porcaro RR. Caracterização microestrutural e estudo cinético de transformação de fases em dois aços standard e premium de aplicação ferroviária. In: Anais do 710 Congresso Anual da ABM; 2016; Rio de Janeiro. São Paulo: ABM; 2016. (vol. 71).

[15] INNOTRACK. D4.6.1: the influence of the working procedures on the formation and shape of the HAZ of flash butt and aluminothermic welds in rails. Bruxelas: European Commission; 2008. INNOTRACK Integrated Project no. TIP5-CT-2006-031415.

[16] Zerbst U, Lunden R, Edel KO, Smith RA. Introduction to the damage tolerance behaviour of railway rails: a review. Engineering 
Microestrutura e Propriedades Mecânicas de um Aço para Trilhos Ferroviários Soldado por Centelhamento

Fracture Mechanics. 2009;76(17):2563-2601. http://dx.doi. org/10.1016/j.engfracmech.2009.09.003.

[17] Silva ALVC, Mei PR. Aços e ligas especiais. 2. ed. São Paulo: Blucher; 2006. $646 \mathrm{p}$.
[18] Moreira LP. Tenacidade à fratura e no crescimento de trinca por fadiga de aços perlíticos de aplicação ferroviária [dissertação de mestrado]. Ouro Preto: Universidade Federal de Ouro Preto; 2015. 